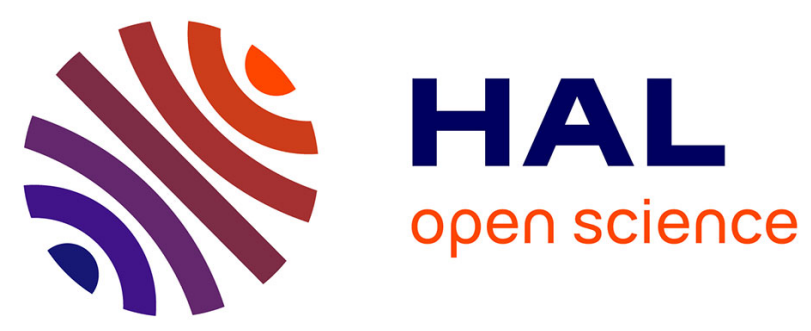

\title{
Assessment from in vivo measurements of thyroid dose due to iodine-131 inhalation when stable iodine has been administered
}

\author{
D. Broggio, P. Teles, T. Vrba, V. Berkovskyy
}

\section{- To cite this version:}

D. Broggio, P. Teles, T. Vrba, V. Berkovskyy. Assessment from in vivo measurements of thyroid dose due to iodine-131 inhalation when stable iodine has been administered. Radiation Measurements, 2019, 127, pp.106144. 10.1016/j.radmeas.2019.106144 . hal-02524804

\author{
HAL Id: hal-02524804 \\ https://hal.science/hal-02524804
}

Submitted on 25 Oct 2021

HAL is a multi-disciplinary open access archive for the deposit and dissemination of scientific research documents, whether they are published or not. The documents may come from teaching and research institutions in France or abroad, or from public or private research centers.
L'archive ouverte pluridisciplinaire HAL, est destinée au dépôt et à la diffusion de documents scientifiques de niveau recherche, publiés ou non, émanant des établissements d'enseignement et de recherche français ou étrangers, des laboratoires publics ou privés.

\section{(c) (1) $\$$}

Distributed under a Creative Commons Attribution - NonCommerciall 4.0 International 


\title{
Assessment from in vivo measurements of thyroid dose due to iodine- 131 inhalation when stable iodine has been administered.
}

\author{
D. Broggio ${ }^{a *}$, P. Teles ${ }^{b}$, T. Vrba $^{c}$, V. Berkovskyy ${ }^{d}$ \\ a Institut de Radioprotection et de Sûreté Nucléaire, IRSN/PRP-HOM/SDI/LEDI, 92262 Fontenay-aux- \\ Roses, France \\ ${ }^{b}$ Grupo de Proteç̧ão e Segurança Radiológica, Centro de Ciências e Tecnologias Nucleares, Instituto \\ Superior Técnico, Pólo de Loures, Estrada Nacional 10, 2695-066 Bobadela LRS Portugal \\ ${ }^{c}$ Czech Technical University in Prague, Břehová 7, 11519 Prague, Czech Republic \\ ${ }^{d}$ Ukrainian Radiation Protection Institute, Ukraine
}

\begin{abstract}
Potassium iodide (KI) is a well-known thyroid prophylactic agent that blocks the incorporation of radioactive iodide in the thyroid; it is generally available for oral administration by the population in case of a nuclear release. However, the blockage provided by $\mathrm{KI}$ is not $100 \%$ effective and therefore activity could still be measured in the thyroid after an intake of radioactive iodine. As a consequence of $\mathrm{KI}$ administration the thyroid retention function and the thyroid dose coefficient are modified. To assess the thyroid dose from in vivo measurements these two quantities must be taken into account.

In this work we considered the inhalation of 131 -iodine by adult, children $(1,5,10$ years-old) and adolescents (15 years). The effect of $\mathrm{KI}$ administration was modeled by a time-dependent blood to thyroid transfer rate coefficient. The model was benchmarked against dose coefficient in the absence of $\mathrm{KI}$ and against the protective effect curves depending on $\mathrm{KI}$ administration time.

This KI specific model was used to provide correction factors for dose assessment. These multiplicative correction factors apply to a "classical" dose assessment, i.e. a dose assessment based on the ICRP default model that ignores the KI effect. This solution has been preferred since it provides ready to use values avoiding implementing the KI specific model. The correction factors depend on the measurement time and on the $\mathrm{KI}$ administration time. They are relatively independent of age and can be described by simple analytic functions. Working examples are provided in this study.

For examples, $\mathrm{KI}$ administration $12 \mathrm{~h}$ before the intake and early in vivo measurements (between $4 \mathrm{~h}$ and $64 \mathrm{~h}$ ) after the intake give correction factors between 1.2 and 15 . For late measurements the correction factors are generally small. If $\mathrm{KI}$ has been taken after the intake the correction factors are also generally small, except for very early measurements.
\end{abstract}

\footnotetext{
*Corresponding author: david.broggio@irsn.fr
} 


\section{Introduction}

After a reactor accident, large quantities of radioactive iodine may be released into the environment. This radioactive iodine may be then incorporated into the human body through inhalation or ingestion, and is a main source of concern in terms of radiation protection (Reiners and Schneider, 2013 ; UNSCEAR 2013). The most commonly used prophylactic agent that blocks the radio-iodine uptake in the thyroid is potassium iodide (KI).

$\mathrm{KI}$, which is normally given in pills, consists of an anhydrous compound containing one atom of potassium and one of stable iodine, it is considered the golden standard in the protection, prevention and treatment of radiation uptake in the thyroid (Blum and Eisenbud 1967 ; WHO 1999 ; Verger et al., 2001). It is considered to be the most effective prophylactic agent for radioactive iodine intakes, and the least likely to induce side effects (Blum and Eisenbud 1967; WHO, 1999; Verger et al., 2001). The effectiveness of the administration of $\mathrm{KI}$ (in single or repeated administration) in terms of uptake blocking has been studied by several authors (Blum and Eisenbud, 1967 ; Zanzonico and Becker 1993; Zanzonico and Becker 2000; Jang et al., 2008).

The amount of administered $\mathrm{KI}$ depends on age, which according to the WHO spans from $16 \mathrm{mg}$ for neonates to $130 \mathrm{mg}$ for adults and adolescents over 12 years-old. The decision for stable iodine administration depends on the estimated dose to the thyroid when no blocking agent is administered. Since the probability of radiation-induced thyroid cancer decreases with age, the WHO recommends to initiate the administration of stable iodine at lower projected thyroid doses for children than for adults (WHO, 1999). Effective dosage must also take into account age, dietary habits, and the thyroid function of the individuals (Verger et al., 2001). For instance, in Poland, after the Chernobyl accident, children aged between 3 to 12 years old were given $50 \mathrm{mg}$, and less than 2 years old were given $25 \mathrm{mg}$ (Nauman and Wolff, 1993).

Even if $\mathrm{KI}$ is an excellent prophylactic agent it is not $100 \%$ efficient, particularly if it has been administered too early or too late relatively to the intake time. In such cases in vivo thyroid measurements could detect radio-iodine in the thyroid. Even if $\mathrm{KI}$ is administered at a proper time it could not be excluded that a large intake would not result in positive measurements. In case of multiple spaced out releases the protective effect could be lost and positive measurement could occur. In (Balonov et al., 2003) it is reported that positive thyroid measurements were obtained despite $\mathrm{KI}$ administration.

Thyroid dose or committed effective dose can be assessed from in vivo measurements. However, since this assessment is based on a biokinetic model that ignores the effect of $\mathrm{KI}$ administration it is not possible to assess the dose from measurement if $\mathrm{KI}$ has been taken. The well-known protective effect curve (Zanzonico and Becker 1993; Zanzonico and Becker 2000), that describes the avoided thyroid dose as a function of KI administration time, is of no help to interpret measurements. Indeed, in case of a positive measurement of a subject who took KI one would need to measure another subject, who was in the same condition than the first one, and who did not take KI, to deduce the dose of the first one. Only in that conditions the protective effect curve could be used.

In this study, the age dependent thyroid retention functions and thyroid dose coefficients when stable iodine was administered are calculated. The case of $\mathrm{KI}$ administration by oral administration and iodine-131 inhalation are considered. The effect of $\mathrm{KI}$ administration is modelled through a time varying transfer rate of radio-iodine from blood to thyroid. The obtained retention function and the thyroid dose 
coefficients can then be used to calculate the dose to the thyroid due to a unit intake. They can also be used to deduce the dose due to a unit content at a given time after intake. Rather than tabulating dose coefficient per unit content for a large set of administration time and measurement time we provide correction factors. The main advantage of this approach is that this correction factors take and analytical form for early measurements and a constant value for late measurements. The dose assessment from measurement is performed as usual except that the dose must be multiplied by the correction factor. Working examples are provided.

\section{Material and methods}

In this section it is shown how to calculate dose in case of stable iodine administration. For that purpose thyroid retention functions are calculated taking into account a time-varying transfer rate between blood and thyroid. Subsequently it is shown how to correct dose assessment from a measurement so that the effect of stable iodine is properly taken into account. A correction factor is thus introduced and it applies to the dose calculated in classical conditions, i.e. when stable iodine is not considered.

\section{1 "Standard" biokinetic model (without KI administration)}

The biokinetic model takes into account the age-specific human respiratory track model of ICRP 66 (ICRP, 1994), the alimentary track model of ICRP 30 (ICRP, 1979) and the age-specific systemic model of iodine of ICRP 56 (ICRP, 1990). The biokinetic model is illustrated in Figure 1 and the age dependent transfer coefficient for the iodine systemic model parameters are given in Table 1.

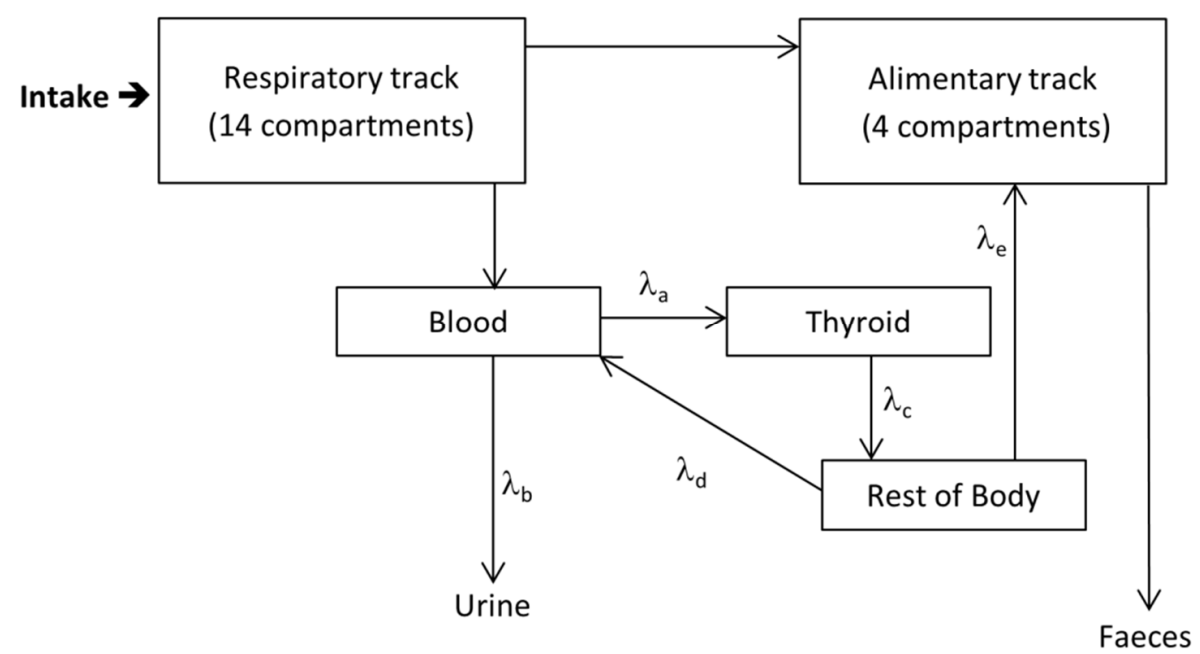

Figure 1. Schematic view of the biokinetic model used in this work. In case of stable iodine administration the blood to thyroid transfer rate becomes time-dependant. 
Table 1. Age dependant biokinetic and dosimetric parameters used in this work for 131-I.

\begin{tabular}{|c|c|c|c|c|c|c|}
\hline Age & $\lambda_{\mathrm{a}}\left(\mathrm{h}^{-1}\right)$ & $\lambda_{\mathrm{b}}\left(\mathrm{h}^{-1}\right)$ & $\lambda_{\mathrm{c}}\left(\mathrm{h}^{-1}\right)$ & $\lambda_{\mathrm{d}}\left(\mathrm{h}^{-1}\right)$ & $\lambda_{\mathrm{e}}\left(\mathrm{h}^{-1}\right)$ & $\begin{array}{c}\text { S-factor } \\
(\mathrm{Gy} /(\mathrm{Bq} . \mathrm{s}))\end{array}$ \\
\hline 1 year & 0.035 & 0.08 & 0.0019 & 0.015 & 0.0039 & $1.74 \mathrm{E}-11$ \\
5 years & 0.035 & 0.08 & 0.0013 & 0.010 & 0.0025 & $9.30 \mathrm{E}-12$ \\
10 years & 0.035 & 0.08 & 0.0005 & 0.0040 & 0.001 & $4.05 \mathrm{E}-12$ \\
15 years & 0.035 & 0.08 & 0.00043 & 0.0035 & 0.00086 & $2.69 \mathrm{E}-12$ \\
Adult & 0.035 & 0.08 & 0.00036 & 0.0019 & 0.00048 & $1.63 \mathrm{E}-12$ \\
\hline
\end{tabular}

\subsection{Biokinetic model with stable iodine administration}

It has been shown that, in case of oral stable iodine administration, the transfer rate from blood-tothyroid suddenly drops well below the normal transfer rate. This variation will depend on the concentration of stable iodide in the blood - as the concentration of stable iodide in the blood increases, the transfer rate will diminish according to the following equation (Zanzonico and Becker, 1993; Zanzonico and Becker, 2000; Jang et al., 2008):

$$
\lambda=0.37 k_{0}[\text { iodide }]^{-0.9}
$$

with $k_{0}=0.0456 \mathrm{~h}^{-1}$ and iodide concentration expressed in $\mu \mathrm{g} / 100 \mathrm{~mL}$.

This means that after $\mathrm{KI}$ administration, the thyroid is almost immediately saturated and further bloodto-thyroid transfers are considerably slowed-down. Then, the thyroid progressively eliminates the stable iodide and the blood-to-thyroid transfer rate increases accordingly, until it reaches the standard value given in Table 1 again. The time equation of iodide concentration in blood is given by (Behling, 1995):

$$
\text { [iodide }]=Q_{u} \exp \left(\frac{-\ln (2) t}{T_{1 / 2}}\right)
$$

where $Q_{u}$ is the initial concentration of iodide in plasma in $\mu \mathrm{g} / 100 \mathrm{~mL}$, and while (Behling, 1995) suggests $T_{1 / 2}=5 \mathrm{~h}$, it is seems better to adopt 6 hours, doing so the time varying transfer rate coefficients obtained in previous works (Jang et al., 2008) can be well reproduced, as shown in Figure 2. This half-life can also be derived considering the 3-compartements model and an exponential fit for the iodide in blood (data not shown).

Table 2 gives age-dependent default values for the initial iodide concentration in plasma, deduced from plasma volumes (ICRP, 2002; ICRP 1975) and the recommended amount of administered stable iodine (WHO, 1999). Hereafter all calculations are carried out using these values.

The time varying blood-to-thyroid transfer coefficient can finally be written as in equations (3) and (4). For stable iodine administration before ${ }^{131}$ I intake:

$$
\lambda(t)= \begin{cases}0.37 k_{0} Q_{u}^{-0.9} \exp \left(\frac{0.9 \ln (2)}{T_{1 / 2}}\left(t+T_{A d m}\right)\right) & \text { if } \lambda \leq \lambda_{a} \\ \lambda_{a} & \text { if } \lambda>\lambda_{a}\end{cases}
$$

For stable iodine administration after ${ }^{131}{ }^{1}$ intake: 


$$
\lambda(t)= \begin{cases}0.37 k_{0} Q_{u}^{-0.9} \exp \left(\frac{0.9 \ln (2)}{T_{1 / 2}}\left(t-T_{A d m}\right)\right) & \text { if } \lambda \leq \lambda_{a} \\ \lambda_{a} & \text { if } \lambda>\lambda_{a} \text { or } t<T_{A d m}\end{cases}
$$

As illustrated in Figure 2, the effect of stable iodine is of about 72 hours. After this delay the blood to thyroid transfer rate becomes equal to its standard value $\lambda_{\mathrm{a}}$. In both equations the time " $\mathrm{t}$ " is relative to the intake and such that at $\mathrm{t}=\mathrm{T}_{\mathrm{Adm}} \lambda$ is minimal and starts increasing slowly.

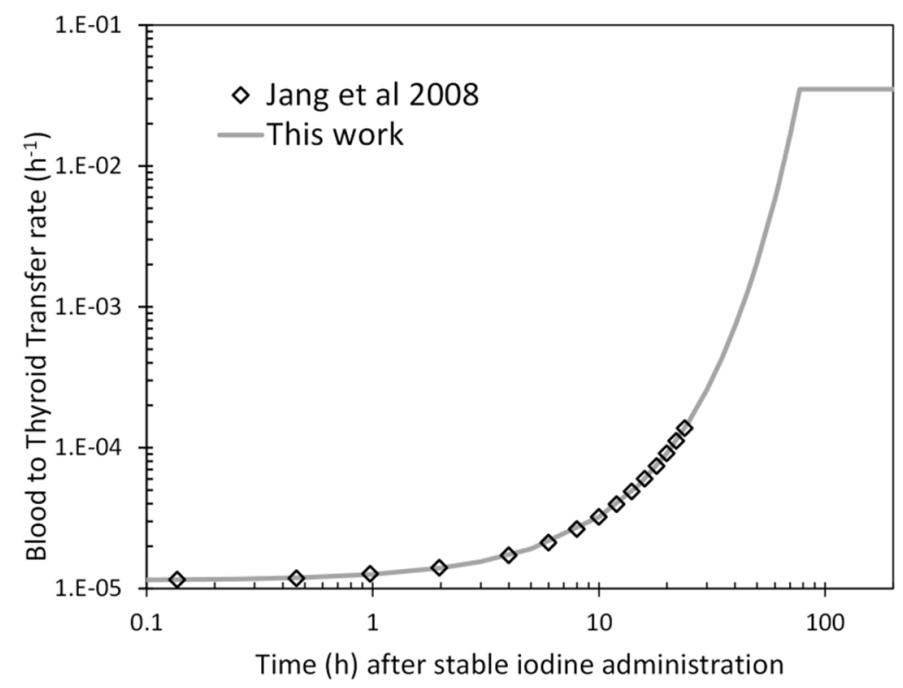

Figure 2. Variation of the blood-to-thyroid transfer rate of iodine, comparison with published values.

Table 2. Age-dependent default values for the initial iodide concentration in plasma

\begin{tabular}{cccc}
\hline age & $\begin{array}{c}\text { plasma volume } \\
{[\mathrm{mL}]}\end{array}$ & $\begin{array}{c}\text { administered } \\
\text { stable iodine weight }[\mathrm{mg}]\end{array}$ & $\begin{array}{c}\text { iodide concentration in } \\
\text { plasma }[\mu \mathrm{g} / 100 \mathrm{~mL}]\end{array}$ \\
\hline 1 year & 450 & 25 & 5556 \\
5 years & 849 & 50 & 5889 \\
10 years & 1421 & 50 & 3519 \\
15 years & 2469 & 100 & 4050 \\
adult & 3000 & 100 & 3333 \\
\hline
\end{tabular}

\subsection{Dosimetric model}

Hereafter we are only concerned with the thyroid dose. The dose to the thyroid (committed up to the age of 70 for children and during 50 years for adults) is calculated according to the ICRP/MIRD formalism (Bolch et al., 2009) that takes into account the resident time of the radionuclides inside the organ. The dose is the product of the cumulated activity $(\tilde{A})$ inside the organ time the S-factor (we neglect crossirradiation due to other organs):

$$
D=\tilde{A} S=I \int_{0}^{70 \text { years }} R(t) d t S
$$

In the above expression we introduced the intake $I(\mathrm{~Bq})$ and the organ retention function $(R(t)$ in $\mathrm{Bq} / \mathrm{Bq}$ of intake). 
The ICRP dose coefficient $\left(h_{70}\right)$ giving the dose per unit intake is thus:

$$
h_{70}=S \int_{0}^{70 \text { years }} R(t) d t
$$

Hereafter, for simplicity, the age-dependent S-factors are calculated from the thyroid weights, as given in (Kilough and Eckerman, 1986), and are reported in Table 1. Whatever the biokinetic model, with or without stable iodine administration, this dosimetric model applies.

As recalled in (Zanzonico and Becker, 2000), the protective effect of $\mathrm{KI}$ administration can be defined as follows:

$$
P E=100 \frac{D-D_{K I}}{D}
$$

where $D$ is the thyroid dose due to unique intake of radioactive iodine when no $\mathrm{KI}$ is administered and $D_{K I}$ is the thyroid dose due to unique intake of radioactive iodine when $\mathrm{KI}$ is taken. The protective effect depends on the time of stable administration relative to the intake. This relation can also be written using the cumulated activity with or without $\mathrm{KI}$ administration:

$$
P E=100 \frac{\tilde{A}-\tilde{A}_{K I}}{\tilde{A}}
$$

The dosimetric model applies to thyroid absorbed dose or thyroid equivalent dose, the numerical values being the same for ${ }^{131}$.

\subsection{Deduction of thyroid dose from measurements}

Following ICRP 78 (ICRP, 1997), if a measurement of the thyroid activity $\left(m\left(t_{\text {meas }}\right)\right.$ in $\left.\mathrm{Bq}\right)$ is carried out at time $t_{\text {meas }}$ after intake the thyroid dose can be calculated as follows :

$$
D=S \frac{m\left(t_{\text {meas }}\right)}{R\left(t_{\text {meas }}\right)} \int_{0}^{70 \text { years }} R(t) d t .
$$

If $\mathrm{KI}$ has been administered at $T_{A d m}$ the retention function is different from $\mathrm{R}(\mathrm{t})$ and we can write:

$$
D_{S I}=S \frac{m\left(t_{\text {meas }}\right)}{R_{K I}\left(t_{\text {meas }}, T_{A d m}\right)} \int_{0}^{70 \text { years }} R_{K I}\left(t, T_{A d m}\right) d t
$$

In Eq. (9) and (10) and hereafter the time of intake is the origin of time, $t_{\text {meas }}$ and $T_{\text {Adm }}$ are measured relatively to the intake time.

At this stage we could simply tabulate dose coefficients and $R_{K I}\left(t_{\text {meas }}, T_{A d m}\right)$ for different administration time and different age groups and the dose could thus be deduced from the measurement. However we believe it is simpler to tabulate correction factors applying to a "classical" dose assessment that ignores the effect of stable iodine administration. Let's consider the same measurement at time $t_{\text {meas }}$, we have:

$$
\begin{aligned}
D_{S I} & =\frac{R\left(t_{\text {meas }}\right) \int R_{K I}\left(t, T_{A d m}\right) d t}{R_{K I}\left(t_{\text {meas }}, T_{A d m}\right) \int R(t) d t} D \\
& =\frac{R\left(t_{\text {meas }}\right)}{R\left(t_{\text {meas }}, T_{A d m}\right)} \frac{\widetilde{A_{K I}}\left(T_{A d m)}\right.}{\tilde{A}} D \\
=C\left(t_{\text {meas }}, T_{\text {Adm }}\right) D &
\end{aligned}
$$


Hereafter we will provide $C\left(t_{\text {meas }}, T_{\text {Adm }}\right)$ for different age groups. If following $\mathrm{KI}$ administration a positive measurement is found the thyroid dose can be assessed classically and then this dose has to be multiplied by the correction factor.

\subsection{Benchmarking}

The calculations for the standard model, i.e., when no KI was administered, will be validated against reference values. For that purpose, the obtained age-specific thyroid retention curves in this work are compared with those provided by the DCAL software (Eckerman et al., 2006). Also, the obtained dose coefficients will be compared with those given in ICRP 71 (ICRP, 1995).

Finally, to complete the validation, the protective effect with our approach will be compared with published values (Zanzonico and Becker, 1993).

\subsection{Practical implementation}

The biokinetic model is solved using a Runge-Kutta method of order 4 (Bellen and Vermiglio, 1996) with a step size of 0.02 , hours between 0 and 300 days, after which the thyroid retention function nearly vanishes. The biokinetic model takes into account the physical decay of ${ }^{131} I$ and considers iodine particles of type $F$, with an AMAD of $1 \mu \mathrm{m}$.

\section{Results}

\subsection{Method validation}

\subsubsection{Retention curves in the standard case (no Kl administration)}

As illustrated in Figure $\mathbf{3}$ there is an excellent overall agreement between the calculated retention curves and those obtained with DCAL. For very long time after intake (typically 200 - 300 days) significant difference can be found but they are of none importance for the calculation of the cumulated activity.
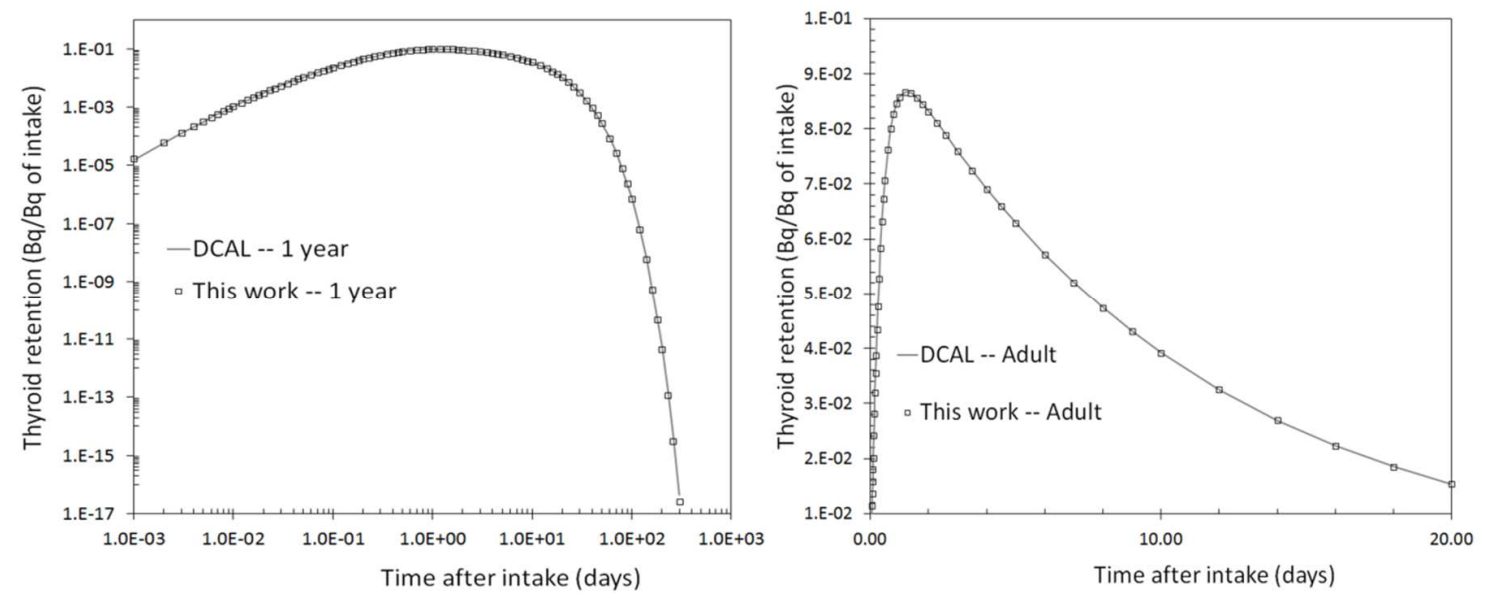

Figure 3. Comparison of thyroid retention curves calculated in this work and obtained with the DCAL software (left: 1 year case, right: adult case) for inhalation of ${ }^{131}$ (type F, AMAD $1 \mu \mathrm{m}$ ) in the standard case (no Kl administration). 


\subsubsection{Dose coefficients in the standard case (no Kl administration)}

The dose coefficients obtained from the S-factors given in Table 1 and the calculated cumulated activity corresponding to the integral of the thyroid retention curves are reported in Table $\mathbf{3}$ and compared with the values given in ICRP 71 (ICRP, 1995). An excellent agreement is found.

Table 3: Thyroid dose coefficients (Sv/Bq or Gy/Bq) for 131-I of type F and AMAD $1 \mu \mathrm{m}$

\begin{tabular}{lccccc}
\hline Age & 1 year & 5 years & 10 years & 15 years & Adult \\
\hline $\mathrm{h}_{50,} \mathrm{~h}_{70}$ (this work) & $1.40 \mathrm{E}-06$ & $7.22 \mathrm{E}-07$ & $3.71 \mathrm{E}-07$ & $2.28 \mathrm{E}-07$ & $1.46 \mathrm{E}-07$ \\
\hline $\mathrm{h}_{50,} \mathrm{~h}_{70}$ (ICRP 71) & $1.40 \mathrm{E}-06$ & $7.30 \mathrm{E}-07$ & $3.70 \mathrm{E}-07$ & $2.20 \mathrm{E}-07$ & $1.50 \mathrm{E}-07$ \\
\hline this work/ICRP 71 & 1.00 & 0.99 & 1.00 & 1.04 & 0.97 \\
\hline
\end{tabular}

\subsubsection{Protective effect}

The protective effect (Eq. 7) is calculated as a function of the administration time (before and after intake) and for all the age groups, considering the $\mathrm{KI}$ amount given in table 2 . The protective effect is compared with the values given in (Zanzonico and Becker, 1993) and the results are shown in Figure 4. Whatever the age there are no significant differences in the protective effect especially if stable iodine is taken after the intake. If stable iodine is taken long before the intake (60 hours) the protective effect can vary of about 10 points depending on the age. We find the well-known trend of the protective effect as a function of the time of administration. If stable iodine is taken $36 \mathrm{~h}$ before the intake the protective effect is greater than $80 \%$. For administration long before intake (72 hours) our calculations predict a less efficient protection than given in (Zanzonico and Becker, 1993). If $\mathrm{KI}$ is taken after the intake the efficiency drops down very fast, for administration at 6 hours post-intake the efficiency is less than $50 \%$, the same trend and values are predicted in (Zanzonico and Becker, 1993).

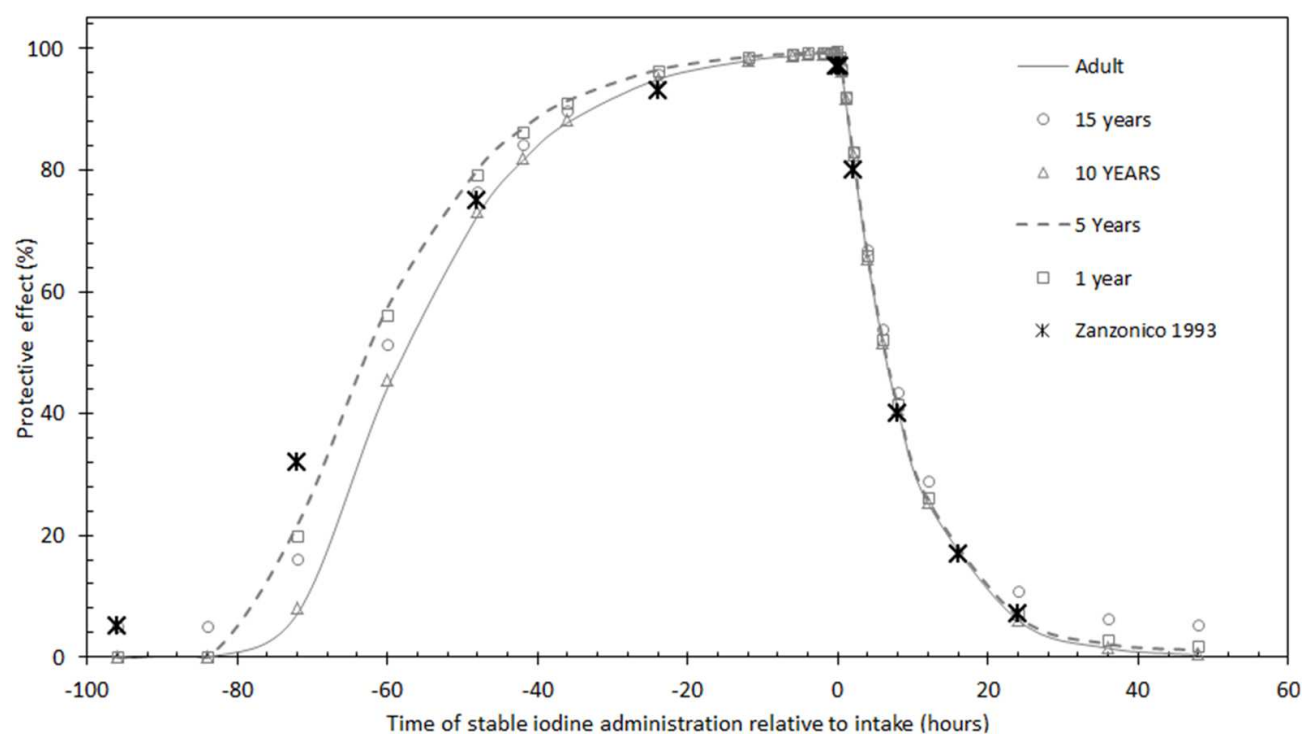

Figure 4. Protective effect as a function of time of $\mathrm{Kl}$ administration for various age groups and comparison with published values. 


\subsubsection{Dose coefficient with stable iodine administration}

The thyroid dose coefficient ( $\mathrm{Sv}$ per Bq of intake) calculated for the adult is shown in Figure $\mathbf{5}$ and compared with the values of (Zanzonico and Becker, 1993). The dose coefficients calculated in this work are smaller than those reported in (Zanzonico and Becker, 1993) by a factor between 2 and 10. It is not surprising since, in fact, the model used in (Zanzonico and Becker, 1993) is for ingestion, as evidenced by the ICRP dose coefficient reported on Figure 5. The dose coefficients for all age groups are tabulated as a function of the administration time in Appendix A.

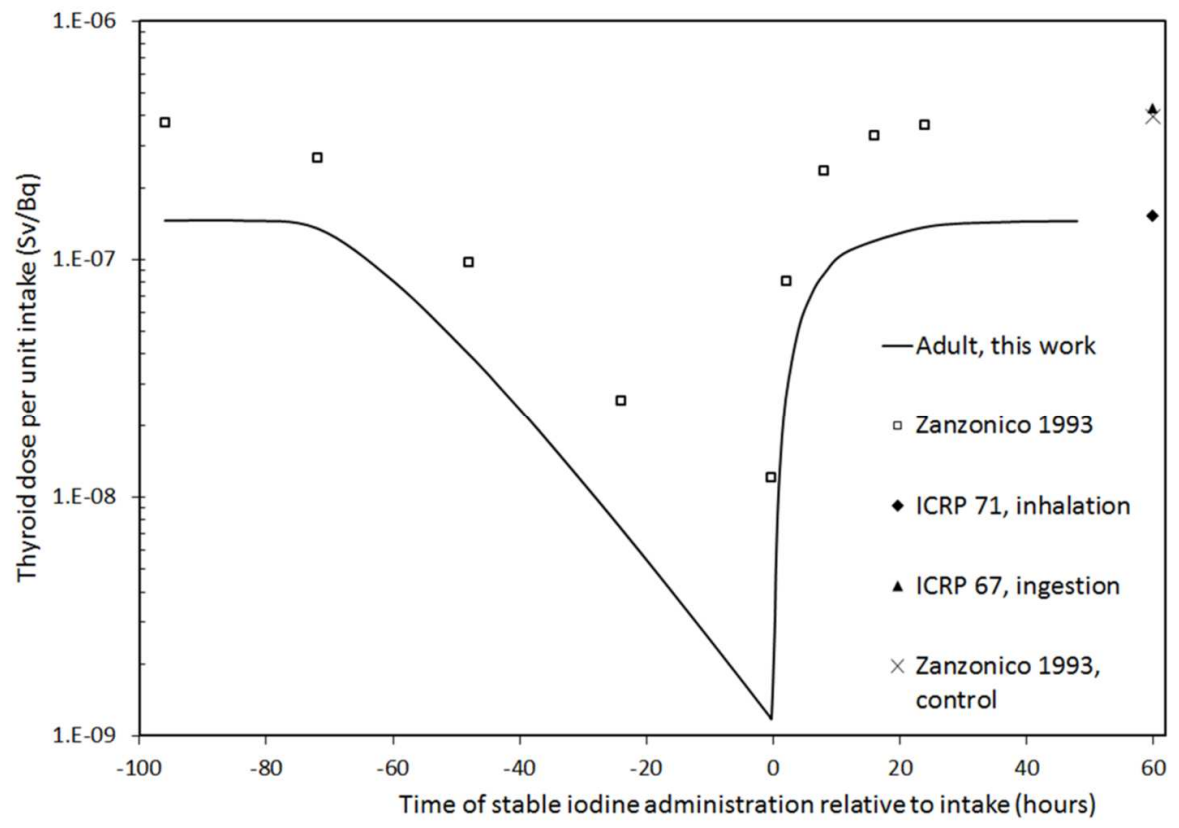

Figure 5. Thyroid dose coefficient for the adult in case of stable iodine administration and comparison with Zanzonico published values. The ICRP and "control" values are shown at 60 days for simplicity but apply in the absence of KI.

\subsection{Retention curves}

The thyroid retention curves obtained in this work are illustrated on Figure 6 for two cases. When stable iodine is taken the thyroid is immediately saturated, the closer is the administration from the intake the more effective is the blockage since the stable iodine remains longer in the thyroid, as compared with an earlier administration. Whatever the administration time the blockage is not total and radioactive iodine accumulates in the thyroid. As illustrated on top of Figure 6, the accumulation is several order of magnitude down to the normal one for administration close to the intake. When the delay between administration and intake increases the retention curve gets closer from the normal retention curve: when the delay is larger than 72 hours the two curves are nearly the same. On the top of Figure 6 a shoulder can be noticed on the 5 lowest retention curves, this shoulder corresponds to the time when stable iodine is no more effective and when the normal biokinetic behavior holds again.

On the bottom of Figure 6 retention curves for stable iodine administration after intake are shown. The retention curves all present the same trend at very short time corresponding to the accumulation of radioactive iodine. When stable iodine is taken the accumulation suddenly stops and the curves become 
flat, at longer time the stable iodine blockage is no more effective and the normal biokinetic behaviour holds again. Radioactive iodine accumulates quite fast in the thyroid and the maximum accumulation occurs at around $24 \mathrm{~h}$, as a consequence is stable iodine is taken after $8-12 \mathrm{~h}$ after the intake the retention curves are quite similar to the normal retention curves.
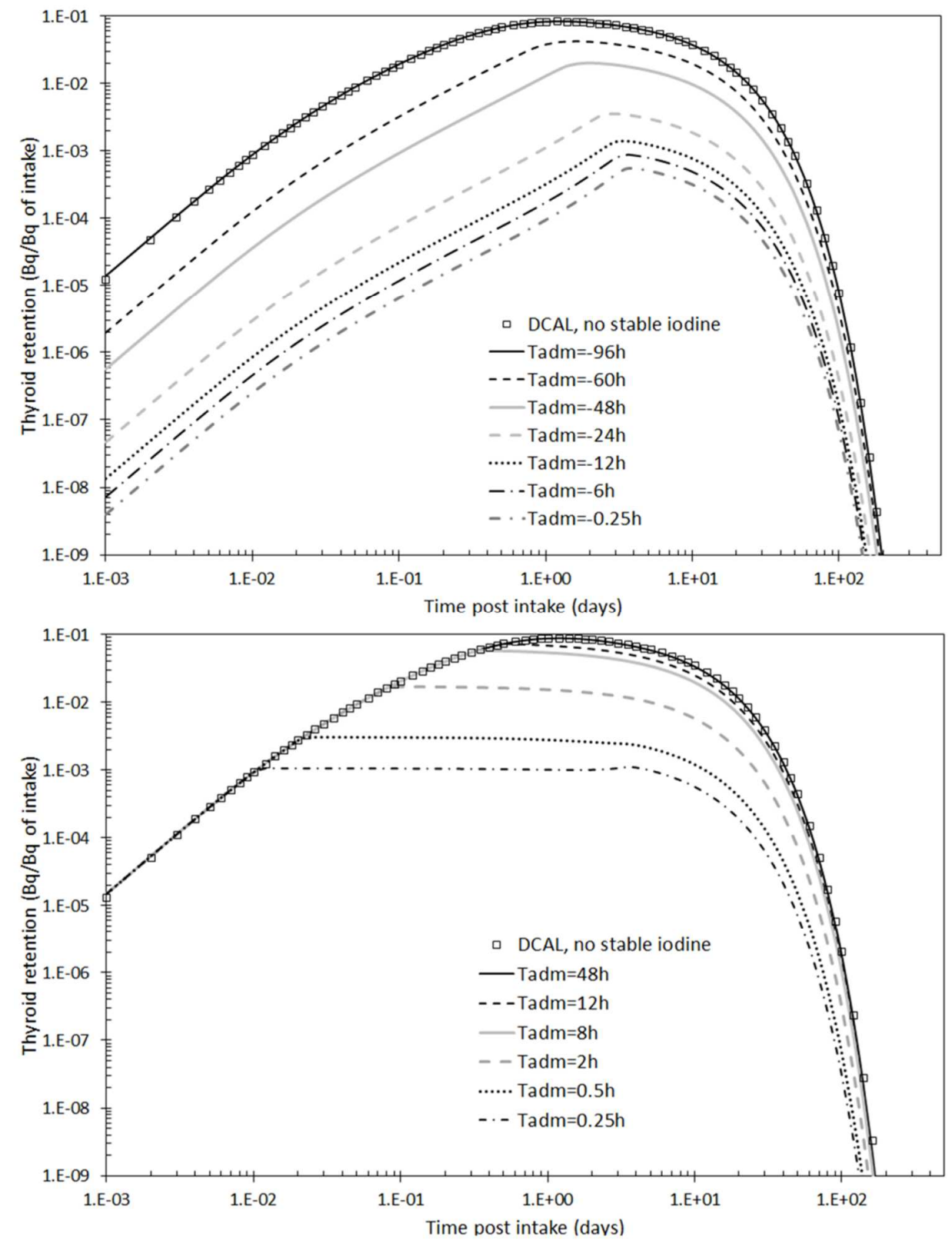

Figure 6. Thyroid retention curves when $\mathrm{KI}$ is administered, as a function of time after intake and for several administration times (relative to intake). Top: administration post intake for the 15 years-old case; bottom: administration after intake for the 5 years-old case.

\subsection{Correction factors}

\subsubsection{Correction factors for stable iodine administration prior to the intake}


The correction factors defined in section 1.4 have been calculated for administration time between $0.25 \mathrm{~h}$ and $96 \mathrm{~h}$ (before the intake) and for measurements time between 0 and 120 days (after the intake ...). Both times are thus given relative to the intake. The correction factors have been calculated for the age groups defined in Table 1.

Inspection of the correction factors reveal that they are relatively independent of the age and that values can be assigned as a function of the administration time $\left(T_{\text {Adm }}\right)$ and measurement time $\left(t_{\text {meas }}\right)$. The rules for the assignment of values are summarized on Figure $\mathbf{7}$ and below. Alternatively a flow chart is given in Appendix B. The rules for the calculation of the correction factor depend primarily on the measurement time as given below. Four classes of measurement times have been selected after a detailed inspections of the data, even if somewhat arbitrary this selection was retained to avoid over-complexity and keep correction factors accurate enough.

1. The measurement time is shorter than $4 \mathrm{~h}$.

The model should be implemented, we do not provide default values since we could not find similar rules as given below. However such early measurements should be quite rare. Another alternative is to use the value of the polynomial given in Table 4 for $T_{\text {meas }}=4 \mathrm{~h}$.

2. The measurement time is between $4 h$ and $72 h$.

a. The administration time occurred before 0 and 72 hours.

The correction factor can be described by a set of polynomial functions. For a given measurement time the correction factor is a polynomial function of the administration time. The equations describing the polynomials are given in Table 4. They have been obtained by fitting the correction factor for the 5 -years old case, which gives a conservative estimate for all ages, as demonstrated on Figure 8.

b. The administration time is greater than $72 \mathrm{~h}$.

A constant value can be assumed, using the value of the polynomial at $T_{\text {Adm }}=72 \mathrm{~h}$.

3. The measurement time is between $72 \mathrm{~h}$ and $84 \mathrm{~h}$.

The correction factor can be obtained by interpolation between the two regions immediately before and immediately after, or alternatively use a conservative estimate.

4. The measurement time is greater than $84 \mathrm{~h}$.

Three constant correction factors can be applied, depending on the administration time. 


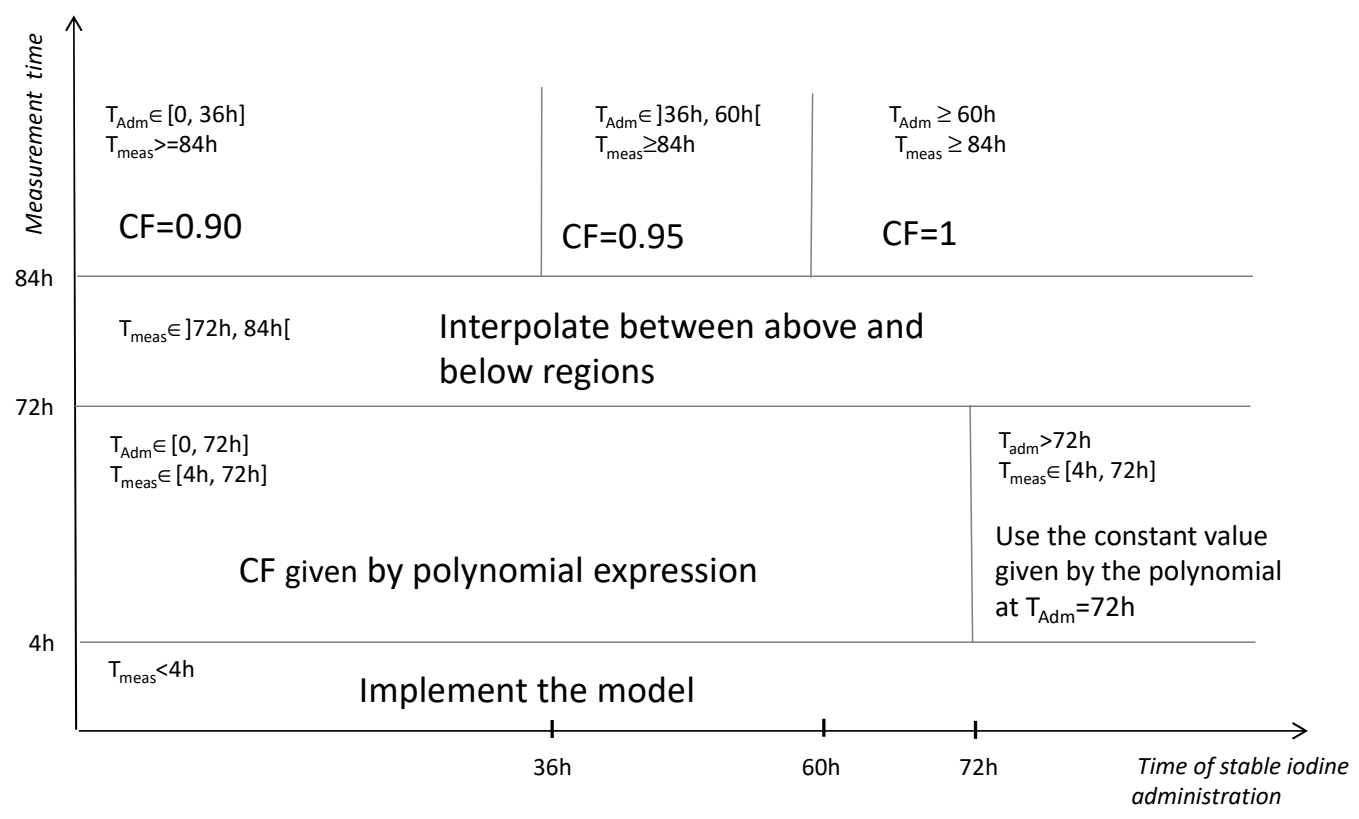

Figure 7. Assignment rule for the correction factor in case of KI administration before the intake.

Table 4. Coefficients giving the correction factor for several measurement times ( $T_{\text {meas }}$ ) as a function of the administration time $\left(T_{A d m}\right)$, for stable iodine administration before intake. The $R^{2}$ coefficient describes the goodness of fit for the 5-years old case. The correction factor applies to all age groups.

\begin{tabular}{|c|c|c|c|c|c|c|}
\hline \multirow[t]{2}{*}{$t_{\text {meas }}(\mathrm{h})$} & \multicolumn{5}{|c|}{$C F=\sum_{\substack{k=0 \\
T_{A d m} \text { in hours }}}^{n} a_{k} T_{A d m}^{k}$} & \multirow[t]{2}{*}{$R^{2}$} \\
\hline & $a_{0}$ & $a_{1}$ & $a_{2}$ & $a_{3}$ & $a_{4}$ & \\
\hline 4 & $2.063 E+01$ & $-4.501 E-01$ & 2.637E-03 & & & 0.9997 \\
\hline 6 & $1.809 \mathrm{E}+01$ & $-3.949 \mathrm{E}-01$ & $2.321 \mathrm{E}-03$ & & & 0.9997 \\
\hline 8 & $1.595 \mathrm{E}+01$ & $-3.485 \mathrm{E}-01$ & $2.055 \mathrm{E}-03$ & & & 0.9997 \\
\hline 10 & $1.412 \mathrm{E}+01$ & $-3.087 E-01$ & $1.828 \mathrm{E}-03$ & & & 0.9997 \\
\hline 12 & $1.256 \mathrm{E}+01$ & $-2.752 E-01$ & $1.642 \mathrm{E}-03$ & & & 0.9998 \\
\hline 16 & $1.005 \mathrm{E}+01$ & $-2.219 \mathrm{E}-01$ & $1.363 \mathrm{E}-03$ & & & 0.9998 \\
\hline 20 & $8.159 \mathrm{E}+00$ & $-1.823 \mathrm{E}-01$ & $1.163 \mathrm{E}-03$ & & & 0.9999 \\
\hline 24 & $6.714 \mathrm{E}+00$ & $-1.520 \mathrm{E}-01$ & $1.012 \mathrm{E}-03$ & & & 0.9999 \\
\hline 32 & $4.702 \mathrm{E}+00$ & $-1.094 \mathrm{E}-01$ & 8.066E-04 & & & 1.0000 \\
\hline 40 & $3.417 E+00$ & $-8.080 \mathrm{E}-02$ & $6.608 \mathrm{E}-04$ & & & 0.9997 \\
\hline 48 & $2.550 \mathrm{E}+00$ & $-5.878 \mathrm{E}-02$ & $5.264 \mathrm{E}-04$ & & & 0.9982 \\
\hline 56 & $1.940 \mathrm{E}+00$ & $-4.052 E-02$ & $3.924 \mathrm{E}-04$ & & & 0.9920 \\
\hline 64 & $1.538 \mathrm{E}+00$ & $-4.000 \mathrm{E}-02$ & $8.242 \mathrm{E}-04$ & $-5.180 \mathrm{E}-06$ & & 0.9988 \\
\hline 72 & $1.227 \mathrm{E}+00$ & $-3.146 \mathrm{E}-02$ & $1.046 \mathrm{E}-03$ & $-1.388 \mathrm{E}-05$ & $6.690 \mathrm{E}-08$ & 0.9988 \\
\hline
\end{tabular}



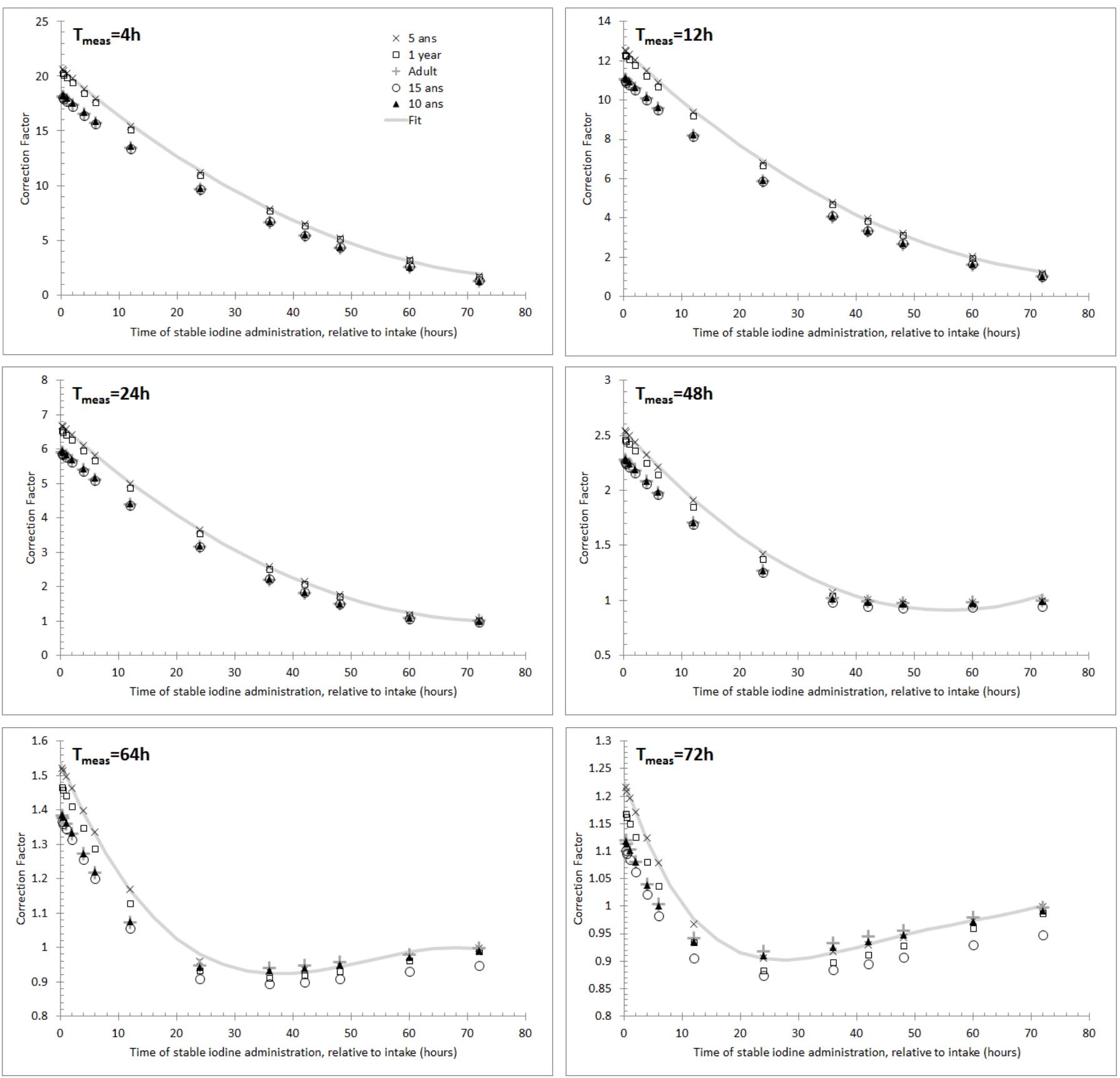

Figure 8. Age specific correction factors as a function of stable iodine administration time and for several measurement times. Stable iodine administration is before the intake. The fitting function has been obtained on the 5 years-old case and applies to all age groups.

\subsubsection{Correction factors for Kl administration after intake}

In the case of stable iodine administration after the intake, only measurement time after the administration are considered $\left(T_{\text {meas }}>T_{\text {Adm }}\right)$, for obvious reasons. Compared with the case of administration prior to the intake the situation is somewhat simpler. Again, it can be shown that the 
correction factors are relatively independent of age. Assignment rules for the correction factor are given in Table $\mathbf{5}$ and alternatively in Appendix B.

1. For measurement times between $4 \mathrm{~h}$ and $48 \mathrm{~h}$ the correction factors can be calculated by a set of polynomial expressions whose variable is $\ln \left(T_{A d m}\right)$. Like for the case of $\mathrm{KI}$ administration before the intake the polynomials are given for several measurement times. The polynomials have been obtained by fitting the data of the adult case, which gives a conservative estimate, as illustrated on Figure 9.

2. For measurement time greater than $48 \mathrm{~h}$ small correction factors can be applied, eventually dependent of the administration time.

Table 5. Coefficients giving the correction factor for several measurement times $\left(t_{\text {meas }}\right)$ as a function of the administration time $\left(T_{\text {Adm }}\right)$, for stable iodine administration after intake. The $R^{2}$ coefficient describes the goodness of fit for the adult case. The correction factor applies to all age groups.

\begin{tabular}{|c|c|c|c|c|c|}
\hline \multirow[t]{2}{*}{$T_{\text {meas }}(\mathrm{h})$} & & $C F=\sum_{k=0}^{n} a$ & $\begin{array}{l}\left(T_{A d m}\right)^{k} \\
\text { and } T_{A d m} \leq T_{m}\end{array}$ & & \multirow[t]{2}{*}{$R^{2}$} \\
\hline & $a_{0}$ & $a_{1}$ & $a_{2}$ & $a_{3}$ & \\
\hline 4 & 3.709E-01 & $-3.946 \mathrm{E}-02$ & $5.035 \mathrm{E}-02$ & $-2.432 \mathrm{E}-02$ & 0.999 \\
\hline 6 & $5.210 \mathrm{E}-01$ & $-6.556 \mathrm{E}-02$ & 7.175E-02 & $-2.636 \mathrm{E}-02$ & 0.997 \\
\hline 8 & $6.414 \mathrm{E}-01$ & $-8.892 \mathrm{E}-02$ & $8.582 \mathrm{E}-02$ & $-2.661 \mathrm{E}-02$ & 0.996 \\
\hline 12 & 8.145E-01 & $-1.232 \mathrm{E}-01$ & $9.972 \mathrm{E}-02$ & $-2.512 \mathrm{E}-02$ & 0.993 \\
\hline 24 & $1.036 \mathrm{E}+00$ & $-1.512 \mathrm{E}-01$ & $9.619 \mathrm{E}-02$ & $-1.862 \mathrm{E}-02$ & 0.989 \\
\hline 48 & $1.087 E+00$ & $-9.743 E-02$ & $4.792 \mathrm{E}-02$ & $-7.628 \mathrm{E}-03$ & 0.989 \\
\hline $48 \mathrm{~h}<T_{\text {meas }} \leq 72 \mathrm{~h}$ & & $\begin{array}{r}\mathrm{CF} \\
\mathrm{CF}=1 \\
\mathrm{C} \\
\end{array}$ & $\begin{array}{l}15 \text { for } T_{A d m} \\
\text { for } 1 \mathrm{~h} \leq T_{A d} \\
1 \text { for } T_{A d m}>4\end{array}$ & & \\
\hline $72 \mathrm{~h}<T_{\text {meas }} \leq 84 \mathrm{~h}$ & \multicolumn{5}{|c|}{$C F=1.05$} \\
\hline$T_{\text {meas }}>84 \mathrm{~h}$ & \multicolumn{5}{|c|}{$\mathrm{CF}=1$} \\
\hline
\end{tabular}



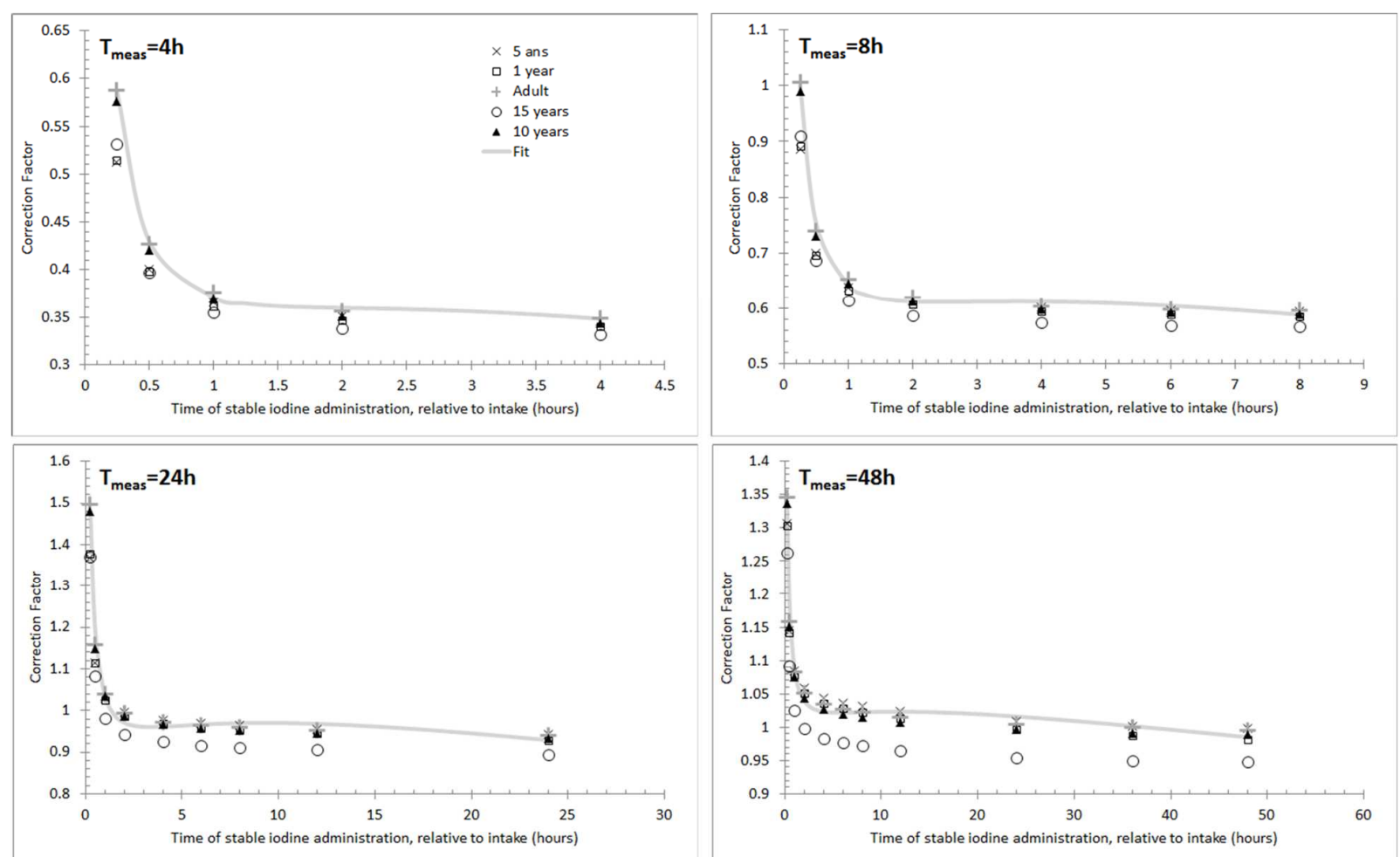

Figure 9. Age specific correction factors as a function of stable iodine administration time and for several measurement times. Stable iodine administration is after the intake. The fitting function has been obtained on the adult case and applies to all age groups.

\section{Discussion}

\subsection{Order of magnitude and trend of the correction factors}

As illustrated on Figure $\mathbf{8}$ the correction factors are greater than 1 for stable iodine administration before the intake. Consequently, interpretation of the measurements without taking into account the effect of stable iodine would lead to an underestimation of the thyroid dose. Whatever the measurement time, the correction factor decreases with the delay between the intake and the administration time, for long delay the correction factors is about 1 , which simply means that the protective effect had vanished at the time of intake. For a given time of administration the magnitude of the correction factor decreases with the measurement time and tends to 1 for long measurement time. This fact is partially explained by the fact that the relative difference between the classical and stable iodine dependent thyroid retention curve is more pronounced at early measurement time than at longer measurement time (cf. for example $T_{\text {Adm }}=48 \mathrm{~h}$, on Figure 6). However, the exact trend of the correction factor depends also on the ratio of the cumulated activity, not only on value of the retention function at a given time. Finally, it must be noticed that for early measurements (let's say between $4 \mathrm{~h}$ and $48 \mathrm{~h}$ ) and for short administration time (i.e. when it is the more effective) the correction factor can be between 2 and 20.

As illustrated on Figure 9, for stable iodine administration after the intake, the correction factors can be greater or smaller than 1. Correction factors are of noticeable importance only for measurements carried out between $24 \mathrm{~h}$ and $48 \mathrm{~h}$ after the intake and if stable iodine was taken at most $1 \mathrm{~h}$ after the intake. 
If the measurements are very early (a few hours after intake) and the administration time of stable iodine close to intake (a few hours before or after) a small uncertainty on the administration time would induce a large uncertainty on the correction factors. From a practical point of view it is however expected than (i) stable iodine is administered several hours before the release and thus intake, (ii) measurements might not be carried out so early.

\subsection{Practical use of correction factors}

Several working examples are given in Appendix C. These working examples are based on the rules given in section 2.3 and Appendix B for calculation of correction factors. For faster implementation these rules could be simplified provided that conservative correction factors are maintained. For a more precise dose assessment, instead of using correction factors the retention curves and dose coefficient should be calculated, as explained in sections 1.2 and 1.3.

\subsection{Limitation of this work and prospect}

In this work the focus was on the interpretation of thyroid measurements and the resulting thyroid dose variation due to $\mathrm{KI}$ administration in the very specific case of ${ }^{131}$ I intake due to inhalation. The interpretation of urine measurements could also provide valuable information for the dose estimation with $\mathrm{KI}$ administration. Also, the committed effective dose should be provided, rather that the thyroid dose, indeed if radioactive iodide is blocked from the thyroid it will be retained elsewhere and, before elimination, will increase the dose to other organs other than the thyroid.

In this work we only deal with inhalation, the same could be done for the ingestion case, eliminating the respiratory model of Figure 1. We have checked on a few examples that the calculated correction factor are of the same order of magnitude that those obtained for inhalation. We also only dealt with ${ }^{131}$ I since it is the iodine isotope the more likely to be measured in case of emergency. Similar correction factors could be obtained for other radio-iodine isotopes, provided that the half-life are taken into account in the biokinetic model.

The approach adopted here concerns acute intake but it can be in principle adapted to chronic intake of radio-iodine or adapted to take into account several administration of KI.

The biokinetic model used in this work can be improved, for example the models presented in (Berkovski, 2002; Leggett, 2017) better describes the short time behavior of iodine in the body and introduce more compartments. Our calculations suggested that the protective effect, when $\mathrm{KI}$ is administered at times greater than 50-60h before intake, is significantly different than the one given in (Zanzonico and Becker, 1993). The exact cause of the difference is not exactly known but several causes are plausible: (i) as evidenced in Figure 5 the Zanzonico calculations are in fact valid for ingestion; (ii) the blood to thyroid transfer rate described by Eq (3) might be inaccurate at long time; (iii) to the best of our knowledge the calculations in (Zanzonico and Becker, 1993) have never been independently benchmarked.

Alternative model have been proposed to describe thyroid blockage following stable iodine administration (Turai and Kanyár, 1986; Leggett, 2010), it would be interesting to compare them with the approach adopted here even if the general trend of thyroid retention functions should be conserved. The model adopted here also assumed that the intake of radioactive iodine is small enough, as compared 
with stable iodine, so that the blood to thyroid transfer rate is modified by stable iodine only but not by the radioactive iodine.

In the model adopted here $\mathrm{KI}$ administration results in an immediate change of the blood to thyroid transfer rate. It might be suitable to dispose of a more realistic model with the transfer rate diminishing fast but continuously from its nominal to minimal values. It can be speculated that such a model would lead to less pronounced differences in the protective effect for short administration time before and after the intake.

\section{Conclusion}

Prophylaxis with potassium iodine (KI) is very efficient and is the best approach to protect the thyroid in the case of a nuclear accident. However, in several cases it cannot be excluded that positive in vivo thyroid measurements could occur even if KI has been administered. In such a case knowing the protective effect of $\mathrm{KI}$ is of no help to interpret the measurements.

We have thus considered the modification of thyroid retention curve induced by $\mathrm{KI}$ administration and provided correction factors that apply to a standard dose evaluation. The correction factors depend on the time of measurement and of the time of $\mathrm{KI}$ administration. For stable iodine administration a few hours before the intake and early measurements ignoring the correction factors would lead to significant thyroid dose underestimation.

\section{References}

Balonov, M., Kaidanovsky, G., Zvonova, I., Kovtun, A., Bouville, A., Luckyanov, N., Voillequé, P., 2003. Contributions of short-lived radioiodines to thyroid doses received by evacuees from the Chernobyl area estimated using early in vivo activity measurements. Radiation Protection Dosimetry, 105 (1-4), 593-599.

Behling, H., Behling, K., Amarasooriya, H., Kotsch, J., 1995. An Analysis of Potassium lodide (KI) Prophylaxis for the General Public in the Event of a Nuclear Accident. NUREG/CR-6310 doi:10.2172/10120351.

Bellen, A., Vermiglio, R., 1996. Some applications of continuous Runge-Kutta methods. Applied Numerical Mathematics, 22(1-3), 63-80.

Berkovski, V., 2002. New iodine models family for simulation of short-term biokinetics processes, pregnancy and lactation. Food and Nutrition Bulletin, 23(3): 87-94.

Blum, M., Eisenbud, M., 1967. Reduction of Thyroid Irradiation from 131I Potassium lodide. Journal of the American Medical Association, 200(12), 1967.

Bolch, W.E., Eckerman, K.F., Sgouros, G., Thomas, S.R., 2009. MIRD pamphlet No. 21: a generalized schema for radiopharmaceutical dosimetry--standardization of nomenclature. Journal of Nuclear Medicine, 50(3), 477-84.

Eckerman, K. F., Legget, R. W., Cristy, M., Nelson, C.B., Ryman, J. C., Sjoreen, A. L., War, R. C., 2006. User's Guide to the DCAL System, Oak Rigde National Laboratory Report, ORNL/TM-2001/190.

ICRP, 1975. ICRP Publication 23, Report on the Task Group on Reference Man.

ICRP, 1979. ICRP Publication 30, Limits for Intakes of Radionuclides by Workers - Part 1. Ann. ICRP 2 (3-4).

ICRP, 1994. ICRP Publication 66, Human Respiratory Tract Model for Radiological Protection. Ann. ICRP $24(1-3)$. 
ICRP, 1995. ICRP Publication 71, Age-dependent Doses to Members of the Public from Intake of Radionuclides: Part 4 Inhalation Dose Coefficients. Ann. ICRP 25 (3-4).

ICRP, 1990. ICRP Publication 56, Age-dependent Doses to Members of the Public from Intake of Radionuclides - Part 1. Ann. ICRP 20 (2).

ICRP, 1997. ICRP Publication 78, Individual Monitoring for Internal Exposure of Workers. Ann. ICRP 27 (34).

ICRP, 2002. ICRP Publication 89, Basic Anatomical and Physiological Data for Use in Radiological Protection Reference Values. Ann. ICRP 32 (3-4).

Jang, M., Kim, H.K., Choi, C.W., Kang, C.S., 2008. Thyroid dose estimation with potassium iodide (KI) administration in a nuclear emergency. Radiation Protection Dosimetry, 132(3), 303-307.

Kilough, G.G., Eckerman, K.F., 1986. Age- and Sex-Specific Estimation of Dose to a Normal Thyroid from Clinical Administration of lodine-131. Oak Ridge National Laboratory Report ORNL/TM9800.

Leggett, R.W. 2010. A physiological systems model for iodine for use in radiation protection. Radiation Research, 174 (4), 496-516.

Leggett, R., 2017. An age-specific biokinetic model for iodine. Journal of Radiological Protection, 37 (4), 864-882.

Nauman, J., Wolff, J., 1993. lodide prophylaxis in Poland after the Chernobyl reactor accident: benefits and risks. American Journal of Medicine 94,524-532.

Reiners, C., Schneider, R., 2013. Potassium iodide (KI) to block the thyroid from exposure to I-131: Current questions and answers to be discussed. Radiation and Environmental Biophysics, 52 (2), 189-193.

Turai, I., Kanyár, B., 1986. Compartment modelling study of stable iodine prophylaxis in relation to the daily iodine supply. Acta Physica Hungarica 59:43-46.

UNSCEAR, 2013. Sources, effects and risks of ionizing radiation - UNSCEAR 2013 report, volume I, report to the general assembly scientific - annex $A$.

Verger, P., Aurengo, A., Geoffroy, B., Le Guen, B., 2001. lodine kinetics and effectiveness of stable iodine prophylaxis after intake of radioactive iodine: A review. Thyroid, 11 (4), 353-360.

World Health Organization (WHO) 1999. Guidelines for lodine Prophylaxis following Nuclear Accidents. WHO report WHO/SDE/PHE/99.6.

Zanzonico, P., Becker, D., 1993. Use of potassium iodide to minimize thyroid radiation from radioactive fall-out. In: Delange, F., Dunn, J., Glinoer, D., eds. Iodine deficiency in Europe: A continuing concern. New York: Plenum Press, pp: 243-253.

Zanzonico, P.B., Becker, D. V., 2000. Effects of time of administration and dietary iodine levels on potassium iodide (KI) blockade of thyroid irradiation by $131 \mathrm{l}$ from radioactive fallout. Health Physics, 78(6), 660-667. 


\section{Appendix A}

Table A-1. Thyroid dose coefficient for various age groups as a function of stable iodine administration time.

Thyroid dose per unit intake (Sv/Bq)

Time of stable iodine administration

1 year $\quad 5$ year 10 years 15 years adult (hours, relative to intake)

\begin{tabular}{|c|c|c|c|c|c|}
\hline-96 & 7.49E-07 & $7.23 \mathrm{E}-07$ & $3.71 E-07$ & $2.28 \mathrm{E}-07$ & $1.45 \mathrm{E}-07$ \\
\hline-84 & 7.49E-07 & 7.23E-07 & 3.71E-07 & $2.28 \mathrm{E}-07$ & $1.45 \mathrm{E}-07$ \\
\hline-72 & 5.99E-07 & $5.66 \mathrm{E}-07$ & $3.40 \mathrm{E}-07$ & 2.01E-07 & $1.35 \mathrm{E}-07$ \\
\hline-60 & $3.28 \mathrm{E}-07$ & 3.07E-07 & $2.03 E-07$ & $1.16 \mathrm{E}-07$ & 8.13E-08 \\
\hline-48 & $1.54 \mathrm{E}-07$ & $1.44 \mathrm{E}-07$ & $9.91 \mathrm{E}-08$ & $5.61 \mathrm{E}-08$ & $3.99 \mathrm{E}-08$ \\
\hline-42 & $1.02 \mathrm{E}-07$ & $9.52 \mathrm{E}-08$ & $6.65 \mathrm{E}-08$ & $3.75 \mathrm{E}-08$ & $2.69 \mathrm{E}-08$ \\
\hline-36 & $6.67 \mathrm{E}-08$ & $6.20 \mathrm{E}-08$ & 4.38E-08 & $2.46 \mathrm{E}-08$ & 1.77E-08 \\
\hline-24 & $2.73 \mathrm{E}-08$ & $2.54 \mathrm{E}-08$ & $1.82 \mathrm{E}-08$ & $1.02 \mathrm{E}-08$ & 7.39E-09 \\
\hline-12 & $1.08 \mathrm{E}-08$ & $1.00 \mathrm{E}-08$ & 7.30E-09 & 4.07E-09 & 2.96E-09 \\
\hline-6 & $6.76 \mathrm{E}-09$ & $6.26 \mathrm{E}-09$ & 4.57E-09 & $2.54 \mathrm{E}-09$ & $1.85 \mathrm{E}-09$ \\
\hline-4 & 5.77E-09 & 5.34E-09 & 3.90E-09 & 2.17E-09 & $1.58 \mathrm{E}-09$ \\
\hline-2 & $4.92 \mathrm{E}-09$ & $4.56 \mathrm{E}-09$ & $3.33 \mathrm{E}-09$ & $1.85 \mathrm{E}-09$ & $1.35 \mathrm{E}-09$ \\
\hline-1 & 4.54E-09 & $4.21 \mathrm{E}-09$ & $3.08 \mathrm{E}-09$ & $1.71 \mathrm{E}-09$ & $1.25 \mathrm{E}-09$ \\
\hline-0.5 & 4.36E-09 & 4.04E-09 & 2.96E-09 & $1.65 \mathrm{E}-09$ & 1.20E-09 \\
\hline-0.25 & $4.28 \mathrm{E}-09$ & $3.96 \mathrm{E}-09$ & $2.90 \mathrm{E}-09$ & $1.61 \mathrm{E}-09$ & $1.18 \mathrm{E}-09$ \\
\hline 0.25 & $1.18 \mathrm{E}-08$ & $1.14 \mathrm{E}-08$ & 6.67E-09 & $3.98 \mathrm{E}-09$ & $2.68 \mathrm{E}-09$ \\
\hline 0.5 & $2.62 \mathrm{E}-08$ & $2.55 \mathrm{E}-08$ & $1.39 \mathrm{E}-08$ & 8.56E-09 & 5.59E-09 \\
\hline 1 & 5.89E-08 & 5.77E-08 & $3.04 \mathrm{E}-08$ & $1.89 \mathrm{E}-08$ & $1.22 \mathrm{E}-08$ \\
\hline 2 & $1.28 \mathrm{E}-07$ & $1.25 \mathrm{E}-07$ & $6.50 \mathrm{E}-08$ & $4.05 \mathrm{E}-08$ & $2.59 \mathrm{E}-08$ \\
\hline 4 & $2.55 \mathrm{E}-07$ & $2.48 \mathrm{E}-07$ & $1.28 \mathrm{E}-07$ & 7.93E-08 & 5.07E-08 \\
\hline 6 & 3.57E-07 & $3.47 \mathrm{E}-07$ & 1.79E-07 & $1.11 \mathrm{E}-07$ & 7.06E-08 \\
\hline 8 & 4.39E-07 & $4.26 \mathrm{E}-07$ & $2.20 \mathrm{E}-07$ & $1.35 \mathrm{E}-07$ & $8.65 \mathrm{E}-08$ \\
\hline 12 & $5.53 \mathrm{E}-07$ & 5.37E-07 & 2.77E-07 & $1.70 \mathrm{E}-07$ & $1.09 \mathrm{E}-07$ \\
\hline 24 & $6.95 \mathrm{E}-07$ & $6.74 \mathrm{E}-07$ & $3.48 \mathrm{E}-07$ & $2.14 \mathrm{E}-07$ & $1.37 \mathrm{E}-07$ \\
\hline 36 & $7.28 \mathrm{E}-07$ & 7.07E-07 & $3.65 \mathrm{E}-07$ & $2.24 \mathrm{E}-07$ & $1.43 \mathrm{E}-07$ \\
\hline 48 & $7.35 \mathrm{E}-07$ & $7.14 \mathrm{E}-07$ & $3.69 E-07$ & $2.27 \mathrm{E}-07$ & $1.45 \mathrm{E}-07$ \\
\hline
\end{tabular}




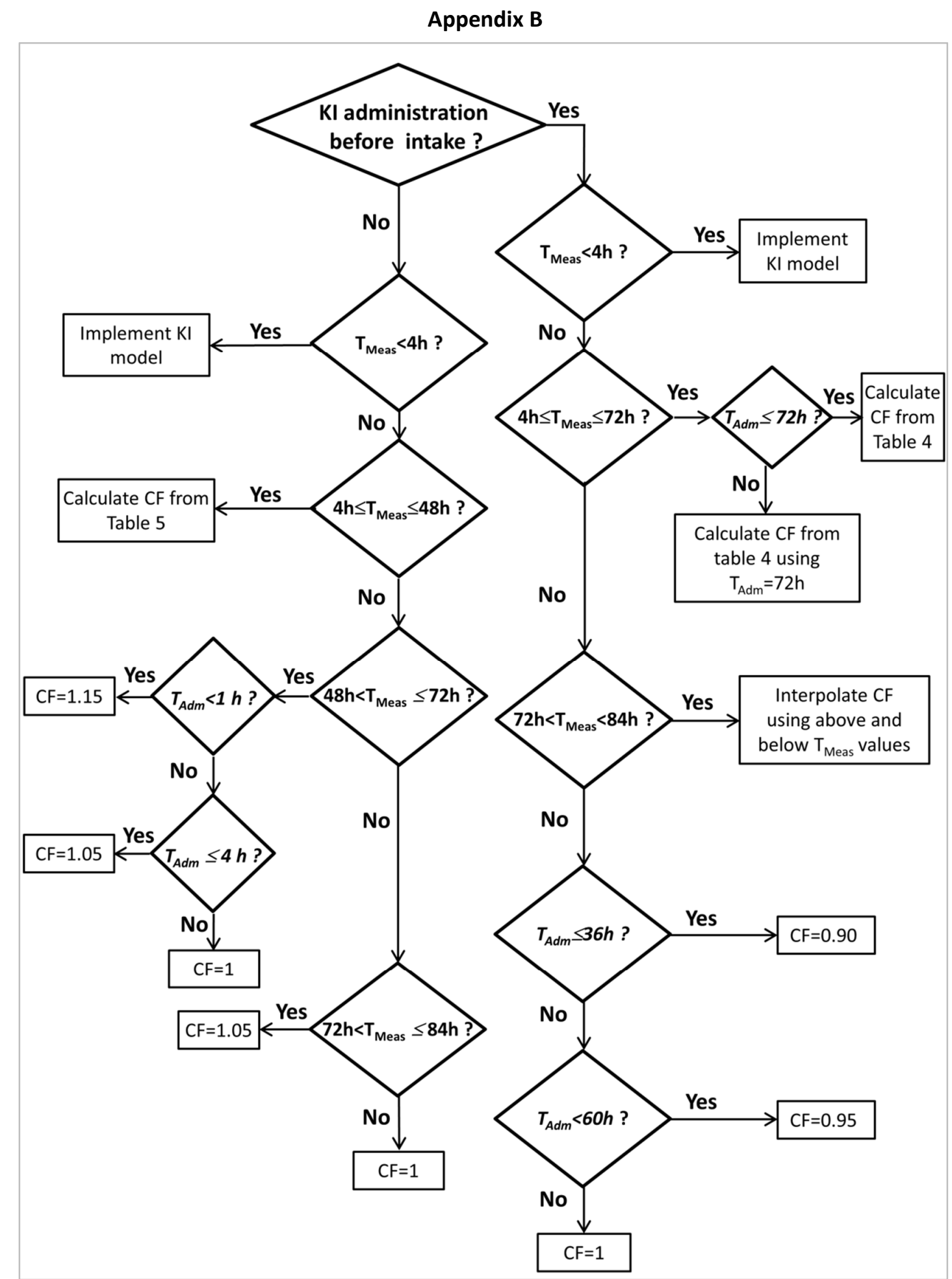

Figure B-1. Flow chart for calculation of correction coefficients when stable iodine has been administered. The administration time $\left(T_{\text {Adm }}\right)$ and measurement time $\left(T_{\text {Meas }}\right)$ are the times elapsed from the intake time. 


\section{Appendix C}

We hereafter give 6 examples of calculation of the correction coefficients. To better illustrate the cases we consider a measurement of $1 \mathrm{kBq}$ in the thyroid and calculate the corresponding doses, with and without correction factors. For simplicity we only consider the adult case.

For dose calculation ignoring stable iodine administration we calculate the intake, as deduced from DCAL's retention curve, and use ICRP 71 dose coefficient (cf. Table 3). Intake and retention are given in Table B-1. The correction factor is provided in Table B-1 and its calculation detailed below.

Table B.1. Summary of the examples detailed below. The calculated thyroid doses correspond to a measurement of $1 \mathrm{kBq}$, of iodine-131 (type $\mathrm{F}, \mathrm{AMAD}=1 \mu \mathrm{m}$ ). A dose assessment corresponding to the measured thyroid retained activity is first performed, ignoring the effect of stable iodine administration, and the correction factor corresponding to the case is then given. The given intake ignores the stable iodine administration and thus does not correspond to the real intake.

\begin{tabular}{ccccccc}
\hline $\mathrm{T}_{\text {meas }}(\mathrm{h})$ & 12 & 36 & 24 & 78 & 8 & 18 \\
$\mathrm{~T}_{\text {Adm }}(\mathrm{h})$ & 8 & 4 & 80 & 12 & 1 & 12 \\
& (prior intake) & (prior intake) & (prior intake) & (prior intake) & (post intake) & (post intake) \\
\hline $\mathrm{R}(\mathrm{t})(\mathrm{Bq} / \mathrm{Bq}$ of intake) & $7.08 \mathrm{E}-02$ & $8.62 \mathrm{E}-02$ & $8.58 \mathrm{E}-02$ & $7.42 \mathrm{E}-02$ & $4.63 \mathrm{E}-02$ & $8.16 \mathrm{E}-02$ \\
Intake $(\mathrm{Bq})$ & $1.41 \mathrm{E}+04$ & $1.16 \mathrm{E}+04$ & $1.17 \mathrm{E}+04$ & $1.35 \mathrm{E}+04$ & $2.16 \mathrm{E}+04$ & $1.23 \mathrm{E}+04$ \\
Thyroid dose $(\mathrm{mSv})$ & 2.1 & 1.7 & 1.8 & 2 & 3.2 & 1.8 \\
\hline $\begin{array}{c}\text { Correction Factor } \\
\begin{array}{c}\text { Corrected dose } \\
(\mathrm{mSv})\end{array}\end{array}$ & 10.5 & 3.7 & 1 & 0.95 & 0.64 & 0.85 \\
\hline
\end{tabular}

\section{Example 1}

- Measurement at $12 \mathrm{~h}$, stable iodine is administered $8 \mathrm{~h}$ before the intake.

The correction factor can be calculated directly from the polynomial found in Table 4 and corresponding to $T_{\text {meas }}=12 \mathrm{~h}$.

We obtain $\mathrm{CF}=10.46$

\section{Example 2}

- Measurement at $36 \mathrm{~h}$, stable iodine is administered $4 \mathrm{~h}$ before the intake.

The correction factor cannot be directly calculated since there is no polynomial function for $36 \mathrm{~h}$. We thus interpolate using two polynomial expressions.

The polynomial for $T_{\text {meas }}=32 \mathrm{~h}$ at $T_{\text {Adm }}=4 \mathrm{~h}$ gives $\mathrm{CF}=4.28$.

The polynomial for $T_{\text {meas }}=40 \mathrm{~h}$ at $T_{\text {Adm }}=4 \mathrm{~h}$ gives $\mathrm{CF}=3.1$.

We perform a linear interpolation at $T_{\text {meas }}=36 \mathrm{~h}$ for the $\mathrm{CFs}$ and find $\mathrm{CF}=3.7$. 


\section{Example 3}

- Measurement at $24 \mathrm{~h}$, stable iodine is administered $80 \mathrm{~h}$ before the intake.

According to Figure 6 the value of the polynomial at $T_{\text {Adm }}=72 \mathrm{~h}$ must be used. Taking the polynomial corresponding to $T_{\text {meas }}=24 \mathrm{~h}$ we find $\mathrm{CF}=1$.

\section{Example 4}

- Measurement at $78 \mathrm{~h}$, stable iodine is administered $12 \mathrm{~h}$ before the intake.

According to Figure 6 we must interpolate between values found in the region corresponding to $T_{\text {meas }}$ $>84 \mathrm{~h}$ and in the region corresponding to $T_{\text {meas }}<72 \mathrm{~h}$.

In the upper region we have $\mathrm{CF}=0.9$.

In the lower region we take the polynomial corresponding to $T_{\text {meas }}=72 \mathrm{~h}$ at the value of $T_{\text {Adm }}=12 \mathrm{~h}$. We find $\mathrm{CF}=1$.

Either we take $\mathrm{CF}=1$ for a conservative estimate or $\mathrm{CF}=0.95$ if we prefer a linear interpolation.

\section{Example 5}

- Measurement at $8 \mathrm{~h}$, stable iodine is administered $1 \mathrm{~h}$ after the intake.

According to Table 5 the correction factor can be calculated with the polynomial function corresponding to $T_{\text {meas }}=4 \mathrm{~h}$ at $T_{\text {Adm }}=1 \mathrm{~h}$.

We find $\mathrm{CF}=0.64$.

\section{Example 6}

- Measurement at $18 \mathrm{~h}$, stable iodine is administered $12 \mathrm{~h}$ after the intake.

According to Table 5 the correction factor must be calculated with a polynomial expression. Since there is no polynomial corresponding to $T_{\text {meas }}=18 \mathrm{~h}$ we interpolate.

For $T_{\text {meas }}=12 \mathrm{~h}$ the polynomial at $T_{\text {Adm }}=12 \mathrm{~h}$ gives $\mathrm{CF}=0.74$

For $T_{\text {meas }}=24 \mathrm{~h}$ the polynomial at $T_{\text {Adm }}=12 \mathrm{~h}$ gives $\mathrm{CF}=0.97$

Linear interpolation at $T_{\text {meas }}=18 \mathrm{~h}$ gives $\mathrm{CF}=0.85$. 